\title{
ETIKA DAKWAH: KONTEKSTUALISASI DAKWAH PROFESIONAL
}

\author{
Edi Amin \\ STAI al-Hikmah Cilandak Jakarta \\ Email: ediamin76@gmail.com
}

\begin{abstract}
This paper would like to see ethics as the cornerstone of propaganda propaganda contextual and professional. Contextual and professional propaganda that is needed now to avoid preaching the old-fashioned, rigid, monotonous, tend to be monologues, patronizing. Desired changes in the mission is the practice and appreciation of religious values in all activities of life of individuals and society. The ethics of propaganda that the focus of the discussion of this writing include: ethical ideals; ethics in sincerity; ethics in religious pluralism; ethics in tauhid; ethics in politics; ethics in globalization. Six ethics are expected to be used as a reference for preachers in building contextual and professional propaganda. Source of this article is the Koran and the Hadith. books and journals, which were analyzed qualitatively.
\end{abstract}

\section{Abstrak}

Tulisan ini ingin melihat etika dakwah sebagai landasan dakwah yang kontekstual dan profesional. Dakwah yang kontekstual dan profesional diperlukan saat ini guna menghindari dakwah yang kolot, kaku, monoton, cenderung monolog, menggurui (top-down). Perubahan yang diinginkan dalam dakwah adalah pengamalan dan penghayatan nilai-nilai agama dalam segala aktivitas kehidupan individu dan masyarakat. Adapun etika dakwah yang menjadi fokus pembahasan penulisan ini mencakup: etika dalam keteladanan; etika dalam keikhlasan; etika dalam pluralisme agama; etika dalam bertauhid; etika dalam politik; etika dalam globalisasi. Enam etika tersebut diharapkan dapat dijadikan acuan bagi da'i dalam membangun dakwah yang kontektual dan profesional. Sumber tulisan ini adalah al-Quran dan Hadis. buku, dan jurnal, yang dianalisis secara kualitatif.

Kata Kunci: Etika, Dakwah, Kontekstualisasi, Profesional 


\section{Pendahuluan}

Fazlur Rahman dalam Major Themes of the Quran menyatakan, "tidak diragukan lagi, bahwa tujuan sentral Al-Quran adalah untuk menciptakan sebuah tata sosial yang mantap dalam hidup di muka bumi, yang adil dan diasaskan pada etika". ${ }^{1}$ Tanpa asas moral yang dipedomani bersama, jangan banyak berharap bahwa keadilan yang menjadi cita-cita abadi umat manusia dapat tercapai. ${ }^{2}$ Etika sebagai pondasi masyarakat memerlukan panduan dan kontekstualisasi sesuai perkembangan manusia. Masyarakat akan pincang jika nilai-nilai etika bersama rapuh, kabur dan sudah tidak dipedomani.

Etika $^{3}$ dalam dakwah bisa berarti kode etik dakwah, yakni aturan main bagi da'i terkait nilai etis dalam dakwah. Ia merupakan moral dalam Islam yang muarannya adalah hati nurani yang berdasar pada akal dan wahyu. ${ }^{4}$ Etika dalam dakwah akan membentuk etika dakwah yang berarti penilaian etis mengenai perilaku dakwah. Sebagaimana dikatakan oleh kalangan ahli politik Barat mengenai etika politik adalah "etbical assesment of political behaviors" (penilaian etis mengenai perilaku politik). ${ }^{5}$

Etika dakwah dalam tulisan ini merupakan sistem nilai atau cara hidup etis dalam dakwah. Al-Ghazali dalam tujuan mempelajari etika lebih setuju bahwa ia akan meningkatkan sikap dan perilaku seharihari yang didasarkan pada pertanggung jawaban pada Tuhan di kemudian hari. Inilah yang menyebabkan etika Ghazali bercorak

\footnotetext{
${ }^{1}$ Ahmad Syafii Maarif, Membumikan Islam (Yogyakarta: Pustaka Pelajar Offset, 1995), 64.

${ }^{2}$ Ahmad Syafii Maarif, "Agama dan Pembangunan: Corak Masyarakat Islam Masa Depan”, Jurnal Ulumul Quran, Vol. III, no. I, 1992, 99.

${ }^{3}$ Dalam tradisi filsafat "etika" lazim dipahami sebagai suatu teori ilmu pengetahuan yang mendiskusikan mengenai apa yang baik dan apa yang buruk berkenaan dengan perilaku manusia. Persoalan etika muncul ketika moralitas seseorang atau suatu masyarakat mulai ditinjau lagi secara kritis. Sedangkan moralitas berkenaan berkenaan dengan tingkah laku yang kongkrit, sedangkan etika bekerja pada level teori. Lihat Paul W. Tailor, Problems of Moral Philosophy, (California: Deckenson Publishing Compant Inc., 1992), 3.

4Pengintegrasian antara akal dan hati nurani (qalbu) dengan petunjuk wahyu akal menghasilkan pemikiran yang tidak hanya mendasarkan pada pertimbangan rasionalitas dan pragmatis semata, tetapi juga pada waktu bersamaan pertmbangan qalbu ikut diperankan. Lihat M. Yunan Yusuf, Internalisasi Etika Islam ke dalam Etika Nasional", Jurnal Dakwah, Kajian dakwah dan kemasyarakatan, Vol. I, No. 3, 1999, 4-5.

${ }^{5}$ A. Muis, Komunikasi Islam (Bandung: Rosda, 2001), 111.
} 
teleologis (aliran filsafat yang mengajarkan bahwa segala ciptaan di dunia ini ada tujuannya), sebab ia menilai amal dengan mengacu kepada akibatnya. ${ }^{6}$ Tujuan utama etika adalah kebahagiaan hidup. Mulyadhi menyimpulkan bahwa etika-yakni filsafat moral atau ilmu akhlak --tidak lain daripada ilmu atau seni hidup (the art of living) yang mengajarkan cara hidup bahagia, atau bagaimana memperoleh kebahagiaan. $^{7}$

Jika ada pertanyaan, mengapa dakwah memerlukan etika? Bukankah seruan dakwah adalah seruan moral agar manusia taat pada Tuhannya? Maka muncul jawaban, benar yang didakwahkan adalah moral, namun muncul pertanyaan lanjutan adakah jaminan para juru dakwah sudah beretika? Tidak jarang ditemukan pendakwah malah menghujat, memprovokasi, ada kalanya menjadi "corong" golongan tertentu, hingga "dicarter" saat kampanye untuk memuluskan partai tertentu. Bahkan mengatasnamakan agama untuk tujuan politik sesaat. Di sinilah wajah agama berubah, ia sebatas simbol tanpa subtansi.

\section{Pengertian Etika Dakwah dan Urgensi Mempelajarinnya}

Seperti halnya dengan banyak istilah, etika berasal dari bahasa Yunani kuno, ethos yang dalam bentuk tunggal memiliki banyak arti: tempat tinggal yang biasa, padang rumput, kandang, kebiasaan, adat, akhlak, watak, perasaan dan sikap cara berpikir. Dalam bentuk jamak ta etha artinya adalah adat kebiasaan. Arti terakhir inilah menjadi latar belakang bagi terbentuknya istilah etika yang oleh Aristoteles sudah dipakai untuk menunjukkan filsafat moral. Jadi etika jika dibatasi pada asal-usul kata ini maka etika berarti ilmu tentang apa yang biasa dilakukan atau ilmu tentang adat kebiasaan. ${ }^{8}$ Ia adalah standarstandar moral yang mengatur perilaku kita: bagaimana kita bertindak dan mengharapkan orang lain bertindak. ${ }^{9}$

${ }^{6} \mathrm{M}$. Abul Quasem, Etika Al-Ghazali, terj. J. Mahyudin (Bandung: Pustaka, 1988), 13.

${ }^{7}$ Mulyadhi Kartanegara, Menembus Batas Waktu, Panorama Filsafat Islam (Bandung: Mizan, 2002), 67.

${ }^{8}$ K. Bertens, Etika (Jakarta: Gramedia Pustaka Utama, 2004), 4.

${ }^{9}$ Deddy Mulyana, "Pengantar Etika Komunikasi: Konstruksi Manusia yang Terikat Budaya", dalam buku Richard L. Johannesen, Etika Komunikasi (Bandung: Remaja Rosdakarya, 1996), v. 
Etika adalah ilmu pengetahuan tentang kesusilaan. ${ }^{10}$ Ahmad Amin mendefinisikan etika sebagai ilmu yang menjelaskan arti baik dan buruk, meneragkan apa yang seharusnya dilakukan oleh manusia kepada manusia lainnya, menyatakan tujuan yang harus dituju dan menunjukkan jalan apa yang seharusnya diperbuat. ${ }^{11}$ Dalam kamus besar Bahasa Indonesia, etika memiliki tiga arti: 1. ilmu tentang apa yang baik dan apa yang buruk dan tentang hak dan kewajiban moral (akhlak); 2. kumpulan asas atau nilai yang berkenaan dengan akhlak; 3. nilai mengenai benar dan salah yang dianut suatu golongan atau masyarakat. ${ }^{12}$

Tulisan ini lebih menekankan pada pengertian ketiga atau terakhir dari aspek kebahasaan di atas, yaitu nilai-nilai atau normanorma etis dalam dakwah. Menurut K. Bertens, arti ketiga atau terakhir juga lebih mendasar. Arti ini juga bisa dirumuskan sebagai 'sistem nilai', atau pola umum atau cara hidup. ${ }^{13}$ Al-Quran dan Sunnah Rasul merupakan acuan etis suatu etika. Majid Fakhry menyatakan bahwa para penulis agama pada periode awal telah memikirkan konsep kunci seperti iman, wara', tha'ah, dan lain-lain, yang sering menggunakan catatan atau merujuk pada al-Quran dan Sunnah untuk mendukung pendapat mereka. ${ }^{14}$

Mempelajari etika bukan hanya mengetahui pandangan agar bertindak tepat dan baik, tetapi juga memengaruhi dan mendorong kehendak agar dapat hidup suci dan menghasilkan kebaikan, kesempurnaan dan bermanfaat bagi sesama. Etika mendorong agar kehendak manusia dapat berbuat baik. Hal ini dapat gagal manakala manusia tidak berhasil dalam menjaga kesucian jiwanya. Ia betul telah berbuat baik, namun ternodai karena tidak semata-mata mencari kesucian, yakni ridha Allah SWT. ${ }^{15}$

"Sekelompok masyarakat tanpa etika adalah masyarakat yang menjelang kehancuran", ucap S. Jack Odell, sebagaimana dikutip

${ }^{10}$ H. De Vos, Pengantar Etika (Yogyakarta: Tiara Wacana, 2002), 4.

${ }^{11}$ Ahmad Amin, Etika (Ilmu Akhlak) (Jakarta: Bulan Bintang, 1995), 2.

${ }^{12}$ Departemen Pendidikan dan Kebudayaan, Kamus Besar Bahasa Indonesia (Jakarta: Balai Pustaka, 1990), 237.

${ }^{13}$ Paul Edwadrs (ed.), The Encyclopaedia of Philosophy, (New York: McMillan Pulishing Co. 1967), 82-83

${ }^{14}$ Majid Fakhry, Etika Dalam Islam (Yogyakarta: Pustaka Pelajar, 1996), 68. lihat pula Mafri Amir, Etika Komunikasi Massa dalam Pandangan Islam, (Jakarta: Logos, 1999), 42.

${ }^{15}$ Majid Fakhry, Etika Dalam Islam (Yogyakarta: Pustaka Pelajar, 1996), 46.

22 | TAJDID Vol. XVI, No. 1, Januari - Juli 2017 
Richard L. Johannesen. Odell melanjutkan, "konsep dan teori dasar etika memberikan kerangka yang dibutuhkan untuk melaksanakan kode etik atau moral setiap orang". Odell meyakini bahwa prinsipprinsip etika adalah prasyarat wajib bagi keberadaan suatu komuntas sosial. Tanpa adanya prinsip-prinsip etika, mustahil manusia dapat hidup harmonis dan tanpa ketakutan, kecemasan, keputusasaan, kekecewaan, pengertian dan ketidakpastian. ${ }^{16}$

\section{Etika Dakwah, Menuju Dakwah yang Profesional}

\section{Etika dalam Keteladanan}

Zaman modern dengan berbagai problematikannya menjadikan manusia mengalami krisis multidimensional, diantarannya adalah keteladanan. Terlebih ketika agama dijadikan kebutuhan sekunder. Maka krisis tersebut semakin menjadi. Tanpa disadari krisis keteladanan telah menyulut krisis moral, dan krisis lainnya.

Islam menetapkan Nabi Muhammad sebagai teladan yang baik. Metode keteladanan dipandang efektif dalam menggembangkan dakwah. ${ }^{17}$ Dalam QS. $A l-A$ b $2 a>b$ : 21, penegasan Nabi Muhammad sebagai teladan yang baik bagi seorang Muslim. Dalam kondisi terpuruknya nilai-nilai keteladanan, maka seorang da’i diharapkan mampu memberikan kontribusi pemikiran dan menunjukkan sikap keteladanan bagi ummat. Seorang da'i hendaknya dapat beristiqamah, memiliki prinsip yang teguh dalam kebenaran, dan terus menguatkan pemahaman keagamannya. ${ }^{18} \mathrm{Keteladanan}$ tersebut dapat tercermin dalam lingkup pribadi, keluarga, dan pergaulan masyarakat luas. Tahapan ini penting mengingat masyarakat yang semakin kritis menyoal berbagai permasalahan sosial.

Tidak mungkin terjadi perubahan pada keluarga atau masyarakat kalau tidak dimulai dari individu. Penguatan personal ditegaskan dalam QS. Al-Māidah: 105, bahwa individu memiliki tanggungjawab secara personal. Dari individu yang kuat inilah diharapkan melahirkan keluarga yang kuat. Seorang anak misalnya, harus memperoleh teladan

\footnotetext{
${ }^{16}$ Richard L. Johannesen, Etika Komunikasi (Bandung: Remaja Rosdakarya, 1996), 6.

17Jum'ah Amin Abdul Aziz, Fiqih Dakwah, Studi Atas Berbagai Prinsip dan Kaidah yang Harus dijadikan Acuan Dalam Dakwah Islamiah, terj. Abdul Salam Maskur (Solo: Intermedia, 1998), 206.

${ }^{18}$ Mustafa Malaikah, Manhaj Dakwah Yusuf Al-Qaradhawi, Harmoni antara Kelembutan dan ketegasan, terj. Samson Rahman, (Jakarta: Pustaka AlKatsar, 2001), Cet. Ke-1, 21.
} 
yang baik sejak dini dari kedua orangtuannya. Masyarakat pun harus memperoleh keteladanan dari pemimpin dan para tokoh agar prinsipprinsip hidup yang bersih, bermoral dan bermartabat dapat terlaksana dalam sebuah bangsa. ${ }^{19}$

Para pemimpin dan pemegang kekuasaan, mempunyai tanggungjawab yang besar dalam proses pembelajaran keteladanan. Sikap dan sifat boros, sombong, korupsi, kolusi, nepotisme, memutarbalikkan hukum, arogansi kekuasaan hendaklah dihindari. Sebaliknya, sikap teguh dalam iman, sederhana, hemat, bersahaja, memihak "wong cilik", menegakkan keadilan, adalah sikap yang seharusnya melekat pada para pemegang amanah kekuasaan. Jika pemimpin memiliki keteladanan yang baik, ini akan efektif bagi terciptannya kehidupan bangsa yang positif dan kondusif. Keteladanan pemimpin memiliki dampak yang efektif. Hal tersebut telah dicontohkan Nabi Muhammad tatkala membangun tatanan masyarakat di Madinah. Nabi menjadikan Al-Quran sebagai pedoman tingkah laku hingga melahirkan akhlak yang terpuji. ${ }^{20}$

\section{Etika dalam Keikhlasan}

Ikhlas adalah segala perbuatan yang dilakukan karena mengharapkan ridha Allah semata-mata. Menurut Ibnu Qayyim alJauziah, seseorang yang ikhlas dalam melakukan perbuatan, tujuan, cita-cita dan amalannya semata-mata karena Allah, dengan pengharapan bahwa Dia akan senantiasa menyertainya. ${ }^{21}$ Ikhlas manakala satu-satunya motif dibelakang amal adalah untuk menyenangkan Allah. Inilah ikhlas yang paling tulus. Jika motif motif tunggal itu adalah untuk menikmati kesenangan di surga atau menghindari hukuman di neraka, maka ikhlas seperti itu lebih rendah tingkatannya. Apalagi jika motifnya untuk keuntungan dunia, maka rusaklah keikhlasannya. Mencampur motif itu itu ada kalanya nyata dan kadang-kadang tersembunyi, sering demikian sukar untuk diketahui sehinggan si penganut merasa bahwa ia melakukan suatu

${ }^{19}$ Jum'ah Amin Abdul Aziz, Fiqih Dakwah, Studi Atas Berbagai Prinsip dan Kaidah, 207.

${ }^{20}$ Said Bin Ali Al-Qahtani, Dakwah Islam Dakwah Bijak, terj. Masykur Hakim dan Ubaidillah, (Jakarta: Gema Insani Press, 1994), Cet. Ke-1, 68.

${ }^{21}$ Lihat Dewan Redaksi Ensiklopedi Islam, Ensiklopedi Islam (Jakarta: Ichtiar Baru Van Houve, 1994), 191. 
amal hanya untuk menyenangkan Allah, tapi nyatannya ia berbuat itu karena alasan yang lain. ${ }^{22}$

Niat memiliki dan menentukan kualitas keikhlasan. Tujuan suatu perbuatan jika niatnya tunggal, hanya untuk menyenangkan Allah, maka ia dianggap sebagai tingkatan ikhlas tertinggi. Niat yang ikhlaspun perlu dipandu dengan sikap istiqamah agar tidak luntur oleh godaan. Pada tingkat pribadi seseorang, keikhlasan terasa sebagai tindakan yang tulus terhadap diri sendiri (true to one's self) dalam komunikasinnya dengan Sang Pencipta dan usaha mendekatkan diri kepada-Nya. Maka keikhlasan dalam beragama adalah juga bermakna ketulusan kepada keutuhan (integritas) yang paling dalam dan diharapkan terwujud dalam sikap yang baik kepada sesama. ${ }^{23}$

Seorang da'i dihadapkan pula pada persoalan profesionalisme di zaman modern ini. Tidak jarang ia menggunakan manajemen. Walau begitu hendaklah ia tetap mematuhi etika. Da'i hendaklah menghindari pengharapan upah yang berlebihan, karena dapat membatalkan dakwah lantaran nego dan tarif yang berlebihan. Da'i hendaklah memiliki sikap itsăr , lebih mementingkan orang lain dari dirinya. Dengan kebajikan ini, orang menahan diri dari yang diingininnya demi memberikannya kepada orang lain yang menurut hematnya lebih berhak. ${ }^{24}$

\section{Etika dalam Pluralisme Agama}

Keaneka ragaman agama melahirkan berbagai persoalan, termasuk dakwah. Agama dengan misi kebahagiaan, bisa berubah menjadi sarana konflik jika masing-masing agama memiliki tafsiran yang eksklusif dari masing-masing agama. Pemeluk agama harus menjadikan misi dan dakwah agamannya dalam kompetisi yang sehat. Tidak harus berkoar dengan berlebihan "ini yang benar", karena menarik simpati terkadang hanya melalui hal-hal yang kecil dan sepele. Inilah yang disebut dengan dakwah bi al-ḥāl (tingkah laku atau

${ }^{22}$ M. Abul Quasem, Etika al-Ghazali, terj J. Mahyudin (Bandung: Pustaka, 1988), 196-197.

23Nurcholish Madjid, Islam Doktrin dan Peradaban: sebuah Telaah Kritis Tentang Masalah Keimanan, Kemanusiaan dan Kemodernan (Jakarta: Paramadina, 2000), 50.

${ }^{24} \mathrm{Ibn}$ Miskawaih, Menuju Kesempurnaan Akblak, terj. Helmi Hidayat (Bandung: Mizan, 1994), 48. 
tindakan nyata) lebih efektif dan berpengaruh dari dakwah bi allisān. ${ }^{25}$

Setiap agama hendaklah menanamkan sikap pluralisme yang positif dengan kaedah selain agama agama sendiri ada agama lain yang harus dihormati. Sikap membenarkan ajaran agamannya, dapat dimengerti. Sikap demikian tentu saja sikap yang terpuji, selama tidak menimbulkan situasi sosial yang destruktif. ${ }^{26}$

Rasulullah SAW. telah mengembangkan pluralisme positif, tepatnya saat beliau merintis dakwah di Madinah yang beraneka ragam suku dan agama. Ia mencanangkan Piagam Madinah (Mitsāq alMadinah) untuk mengikat keamanan, persatuan dan pertahanan dari berbagai gangguan. ${ }^{27}$ Dengan perjanjian yang merupakan manifesto politik penting ini, Nabi berhasil menyatukan penduduk Madinah yang berbeda agama dan suku. Dokumen politik ini mempunyai arti yang penting dalam perjalanan sejarah dakwah Islamiyah. ${ }^{28}$

Nabi Muhammad tidak pernah merekayasa agar mereka yang berbeda suku dan agama dan mereka minoritas, dikuciltan atau ditindas. Mereka yang berbeda dirangkul, saling bahu membahu dari serangan musuh dan mempertahankan Madinah. Tidak ada upaya hegemonis, padahal Islam semakin kuat. ${ }^{29}$ Menurut Natsir, iman seseorang hanya dapat ditumbuhkan dalam suasana bebas, sunyi daripada tekanan dan paksaan. ${ }^{30} \mathrm{~N}$. Tamara menyatakan bahwa dalam Islam, keragaman budaya lokal selalu ditempatkan dalam rangka membangun peradaban global. ${ }^{31}$

Dakwah dalam lingkup agama merupakan sarana penyebarluasan dan sosialisasi. Kemerdekaan beragama hendaklah dipahami dan

${ }^{25}$ Lihat M. Yunan Yusuf, "Dakwah bi-Al-Hāal", Jurnal Dakwah Kajian dan Kemasyarakatan, Vol. 3. No. 2, November 2001, 32.

${ }^{26}$ Komaruddin Hidayat dan M. Wahyuni Nafis, Agama Masa Depan, Perspektif Filsafat Parenial (Jakarta: Paramadina, 1995), 70. 13.

${ }^{27}$ Fazlur Rahman, Islam, terj. Ahsin Muhammad (Bandung: Pustaka, 1997),

${ }^{28}$ A. Hasjmy, Dustur Dakwah Menurut Al-Quran (Jakarta: PT. Bulan Bintang, 1994), 292.

${ }^{29}$ Piagam madinah dan terjemahannya dapat dilihat pada Ahmad Sukadja, Piagam Madinah dan Undang-Undang Dasar 1945, Kajian Perbandingan Tentang Dasar Hiddup Bersama Dalam Masyarakat yang Majemuk (Jakarta: UI-Press, 1995), 47-57.

${ }^{30}$ M. Natsir, Fiqhud Dakwah (Jakarta: Yayasan Cipta Selecta, 2000), 123.

${ }^{31}$ Nasir Tamara dkk., Agama dan Dialog Antar Peradaban Jakarta: Paramadina, 1996), xxii. 
menjadi pegangan erat bagi bagi juru dakwah. Dakwah adalah upaya penyebarluasan dan media informasi, agama adalah pesan (nasehat). Tidak ada paksaan dalam dakwah. ${ }^{32}$ Dakwah dengan cara persuasif dan simpatik jauh lebih efektif. ${ }^{33}$ Keberhasilan atau kegagalan dakwah bukanlah tanggung jawab da'i, intervensi Tuhan berperan dalam perolehan hidayah. ${ }^{34}$ Dengan memahami kemerdekaan beragama, seorang juru dakwah diharapkan mampu melakukan tugas dakwah dengan bijak, serta memiliki strategi yang handal guna pencapaian misi agama. Uslūb bahasa yang persuasif seperti: qaulan balighā, qaulan layyinā, qaulan maisūrā, qaulan karìmā, qaulan syadidā yang sesuai dengan engan objek dakwah juga hendaknya dipahami. ${ }^{35}$

4. Etika dalam Bertauhid

Di zaman modern, umat banyak mengalami krisis moral, keteladanan dan juga krisis tauhid. Kehidupan yang materialistis dan konsumtif memperparah problem masyarakat modern. Oleh sebab itu penguatan pada tauhid merupakan sebuah keniscayaan. Nilai tauhid mengajarkan bahwa Allah adalah tujuan, tempat bersandar dan mengabdi.

Dalam Al-Quran, Tuhan memberikan amanat-Nya kepada manusia, amanat yang tidak mampu dipikul oleh langit dan bumi (QS. $A l-A h z a \bar{b}$ : 72). Hanya manusia yang mampu mewujudkannya dengan kemungkinan melakukan atau tidak. Kemerdekaan manusia untuk mematuhi perintah Tuhanlah yang menjadikan pelaksanaan perintah moral. ${ }^{36}$

Kedekatan manusia dengan Tuhan berdampak positif, dan sebaliknya. Karena seorang manusia tidak dapat memilih untuk menjadi suci semaunnya, tetapi dapat mencapai kesucian moral

${ }^{32}$ Nurcholish Madjid, "Beberapa Renungan Tentang Kehidupan Keagamaan Untuk Generasi Mendatang", Ulumul Quran Jurnal Kebudayaan dan Peradaban, Vol. IV, No. 1, 1993.

${ }^{33}$ Lihat QS. Āli-'Imrān: 159.

${ }^{34}$ Lihat QS. 42: 48; 10: 99, sebagaimana dikutip oleh Ismail R. Al-Faruqi dan Lois Lamya Al-Faruqi, Atlas Budaya Islam, Menjelajah Khazanah Peradaban Gemilang, terj. Ilyas Hasan (Bandung: Mizan, 1998), 153.

${ }^{35}$ Lihat Achmad Mubarak, Psikologi Dakwah (Jakarta: Pustaka Firdaus, 1999), 200.

${ }^{36}$ Ismail R. Al-Faruqi dan Lois Lamya Al-Faruqi, Atlas Budaya Islam, 117. 
melalui kekuasaan Tuhan. ${ }^{37}$ Sikap tauhid akan menghasilkan pribadi yang tunduk pada Allah SWT. rasa ketergantungan kepada Zat Yang Tunggal ini menyebabkan seseorang berani menghadapi tantangan hidup dengan penuh semangat dan bergairah. Setiap ujian dan tantangan akan dirasakannya sebagai kesempatan untuk membuktikan pengabdian kepada-Nya dengan penuh ikhlas. Ia penuh keyakinan bahwa Allah Maha Adil dan senantiasa bersama hamba yang mentatati-Nya. Keberhasilan dari ujian, tantangan, atau menunaikan sebuah tugas dan ibadah akan menghasilkan kebahagiaan yang intens. ${ }^{38}$

Mengesakan Allah (tauhid) dan menolak penyekutuan (syirik) terhadap-Nya merupakan doktrin terpenting yang mendominasi pemahaman-pemahaman dan ajaran-ajaran agama samawi. Hal itu juga merupakan asas segala macam ilmu dan ajaran Ilahiyah yang dibawa oleh para Nabi dan Rasul. Tidak seorangpun berbeda pendapat dalam pokok-pokok (ușū $)$. Mereka semua mengesakan Allah SWT. dari segi Zat-Nya, perbuatan-Nya serta ibadah kepadaNya. ${ }^{39}$

Menghadapi fenomena di era modern ini, fenomena syirik tidak lagi penyembahan terhadap patung atau berhala di era jahiliyah seperti saat Nabi Muhammad diutus. Istilah "kekuasaan yang dituhankan", "materi yang dituhankan", merupakan bentuk kesyirikan dan penyimpangan tauhid. Oleh sebab itu, seorang juru dakwah hendaklah dapat mengambil langkah-langkah: Pertama, menjelaskan dan meyakinkan pada umat bahwa tauhid atau mengesakan Allah adalah pondasi terpenting dalam ajaran Islam. Nabi Nuh misalnya, digambarkan dalam Al-Quran: "dan sesungguhnya telah kami utus Nuh kepada kaumnya. (Ia berkata): "sesungguhnya aku memberi peringatan yang nyata kepadamu. Yakni, janganlah kalian menyembah (beribadah) kecuali hanya kepada Allah..."

\section{Etika dalam Politik}

Hiruk pikuk dunia modern tidak terlepas dengan situasi politik. Di Indonesia yang menganut asas demokrasi pancasila, kondisi politik

${ }^{37}$ Lihat Marshall G.S. Hodgson, The Venture of Islam, Islam, Iman dan Sejarah dalam Peradaban Dunia, terj. Mulyadhi Kartanegara (Bandung: Mizan, 2002), 20.

${ }^{38}$ Imaduddin Abdulrahim, "Sikap Tauhid dan Motivasi Kerja", Jurnal Ulumul Qur'an, Vol. II, No. 6, 1990, 43.

${ }^{39}$ Ja'far Subhani, Studi Kritis Fabam Wababi, Taubid dan Syirik, terj. Muhammad Al-Baqir (Bandung: Mizan, 1996), 13.

28 | TAJDID Vol. XVI, No. 1, Januari - Juli 2017 
dari aspek keamanan cukup kondusif. Kegaduhan politik tidak menjadikan bangsa ini mudah terpuruk. Konsep bhenika tunggal ika nampaknya cukup efektif sebagai perekat antar suku, golongan dan agama untuk hidup rukun dalam naungan pancasila. Namun demikian banyak hal yang masih perlu dibenahi, mulai dari penegakkan hukum, sistem pemerintahan yang bersih serta sikap kenegarawanan bagi para elit politiknya.

Banyak dijumpai wajah-wajah santri menjadi politikus di negeri ini, di satu sisi umat Islam bangga dengan eksistensinya. Namun, jika elit tersebut tidak dapat memberikan contoh teladan yang baik, maka dapat menjadi bumerang bagi pengembangan dakwah. Maka ada pula tokoh-tokoh Islam yang tidak mau terjun ke kancah politik karena dinggap rentan sikap oportunis. Di sinilah etika dakwah masuk dalam ranah politik, usaha membingkai politik dengan etika dakwah dalam memandu para politikus agar tidak kebablasan. Politik tujuanya adalah kekuasaan, namun kekuasaan bukanlah ujung, tapi hendaklah dimaknai sebagai awal sebuah perjuangan. Perjuangan yang berhasil manakala ada keikhlasan, persatuan, dan persaudaraan.

Bahtiar menawarkan hubungan agama dan negara yang sinergis atau integratif. mua rakyat memiliki hak berpolitik, menuju banga yang sejahtera dan, adil dan damai. Perbedaan partai politik, seharusnya tidak menjadikan perpecahan dan tindakan anarkis. Beda dalam satu tujuan yaitu pengabdian dan iman. ${ }^{40}$ Perbedaan artikulasi perjuangan merupakan aset bagi tumbuhnya sebuah sinergi sosial dalam rangka mewujudkan kehidupan yang beradab dan penuh rahmat. Jika hal ini tidak dapat terlaksana dengan baik, maka akan ada benturan antara agama dan negara.

Dengan kesadaran moral dalam memaknai perjuangan politik, maka tatanan masyarakat yang adil dan makmur di bawah ridha Ilahi dengan sendirinya akan tercapai. Pancasila sebagai landasan bernegara menurut Kunto bersifat teodemokrasi, yang mana kekuasaan itu dibatasi dari atas oleh Tuhan (yang dalam Islam disebut syari'ah, atau dharma dalam Hindu) dan dari bawah oleh rakyat. ${ }^{41}$

Iqbal menyatakan bahwa sekembalinya Nabi pasca Mi'raj bersifat kreaktif. Nabi kembali untuk menempatkan dirinya dalam putaran

${ }^{40}$ Bahtiar Effendy, Islam dan Negara, Transformasi Pemikiran Praktek Politik Islam dan Indonesia (Jakarta: Paramadina, 1998), dalam resensi yang ditulis Edi Amin, "Konvergensi Islam dan Negara." Kompas, (Jakarta, 27 Desember 1998).

${ }^{41}$ Kontowijoyo, Identitas Politik. Umat Islam (Bandung: Mizan, 1997), 61-62. 
waktu dengan tujuan mengendalikan kekuataan-kekuatan sejarah dan dengan hal tersebut ia dapat mencipta krektifitas yang segar. Di sini kita dapat menyimak dengan jelas bahwa misi dakwah seorang nabi adalah misi kemanusiaan, misi sejarah dengan dimensi yang sangat luas. Politik hanyalah satu dimensi dari kegiatan dakwah yang serba meliputi. ${ }^{42}$ Walaupun demikian, politik memiliki peran yang signifikan dalam dakwah. Bukankah Nabi pemimpin spiritual dan kepala negara sekaligus? Negara yang ideal, akan menempatkan agama di atas segalanya. Agama dijadikan imam, bukan lipstik.

\section{Etika dalam Globalisasi}

Arus modernisasi dengan kemajuan teknologi dan ilmu pengetahuan menjadikan dunia semakin sempit, tanpa sekat. Globalisasi telah menciptakan global village, yang tanpa sekat. Fenomena tersebut memunculkan problm tersendiri dalam dakwah. Di satu sisi dakwah terbantu dengan mudahnya komunikasi, namun di sisi lain tantangan dakwah semakin berat. Budaya asing memerlukan saringan hingga tidak berpengaruh buruk bagi budaya bangsa yang sudah mapan. Formulasi dakwah yang tepat semakin mendesak untuk direalisasikan. Formulasi tersebut tentunya mengacu pada etika global yang ada, agar format dakwah yang ada tidak tidak keluar dari nilai etis internasional.

Etika global menekankan perlu dikembangkannya komitmen umat manusia kepada budaya baru yang berwajah lebih manusiawi. Komitmen tersebut merupakan arah pasti yang dapat membimbing manusia menuju satu kemanusiaan, satu peradaban, satu masa depan. Arah-arah pasti tersebut mencakup: pertama, komitmen terhadap budaya tanpa kekerasan dan penghormatan terhadap hidup. Komitmen tersebut dimaksudkan sebagai kerangka etik untuk mengeliminasi segala bentuk permusuhan, kebencian, dan kekerasan baik antar orang perorang maupun antara bangsa, suku bangsa dan agama. Dalam bahasa agama komitmen ini merupakan pengejawantahan dari perintah "jangan membunuh". Kedua, komitmen kepada budaya solidaritas, dan tata ekonomi yang adil. Komitmen ini merupakan solusi etik terhadap segala bentuk eksploitasi manusia atas manusia lain, kemiskinan dan kesenjangan sosial-ekonomi antara kaya-miskin. Komitmen tersebut merupakan

\footnotetext{
${ }^{42}$ Pernyataan Iqbal tersebut terdapat dalam bukunya The Reconstruction Religious Thought in Islam, oleh Ahmad Syafii Maarif, Membumikan Islam (Yogyakarta: Pustaka Pelajar, 1995), 114.
} 
pengejawantahan dari perintah agama "jangan mencuri!". Ketiga, komitmen kepada budaya toleransi dan kejujuran. Prinsip etik, yang paralel dengan ajaran agama "jangan bohong"!, dimaksudkan sebaagai antitesis terhadap kecurangan, kemunafikan, dan demagigi, terutama dalam bidang politik. Keempat, komitmen kepada budaya persamaan dan kemitraan antara wanita dan pria. Nilai etika ini merupakn penjabaran terhadap perintah agama 'jangan berzina”!, yang termanifestasi dalam berbagai bentuk eksploitasi dan diskriminasi seksual dewasa ini. ${ }^{43}$

Dari pemahaman etika global tersebut tersebut, memunculkan etika dakwah dalam globalisasi, diantarannya: pertama, mengedepankan serta menebarkan kasih sayang sesama manusia, sebagai pengejawantahan dari nilai rahmatan lil 'alamin. Sebaliknya sikap keras, kasar dan sombong justru akan merugikan dakwah. Allah menegur orang-orang sombong dalam firmannya" Janganlab engkau memalingkan mukamu terbadap manusia (karena sombong) dan janganlah engkau berjalan di atas bumi dengan angkuh. Sesungguhnya Allah tidak menyukai orang-orang sombong lagi melampaui batas.” (QS. Al-Luqmān: 18). Kedua, mengedepankan diplomasi dan komunikasiserta menjauhi sikap diskriminatif dan stereotipe. Diplomasi dan komunikasi yang baik, akan menimbulkan efek positif dan simpatik mad'u. Selanjutnya sikap simpatik tersebut dapat meningkat pada rasa keingintahuan akan mempelajari Islam.

Quraish shihab berpendapat, bahwa dalam rangka mewujudkan jembatan antara agama (dakwah) dan kehidupan kontemporer maka ada tiga bidang yang menonjol yang mana ajaran agama dapat berperan: pertama, mewujudkan satu kekuatan pendorong bagi setip pribadi dan masyarakat guna meningkatkan amal usaha dan kreasi mereka. Kedua, mewujudkan isolator-isolator anatara pribadi-pribadi dan menghindari terjadinya penyelewengan-penyelewengan. Ketiga, memelihara satu tingkat etik dalam melaksanakan tugas sehari-hari.44

\section{Kesimpulan}

Berbagai persoalan dakwah di era modern ini memerlukan panduan etis untuk mencari solusinya. Etika dakwah dapat berfungsi sebagai upaya mengkaji, mengoreksi dan mengkritisi kerja dakwah

\footnotetext{
${ }^{43}$ M. Din Syamsuddin, Etika Agama dalam Membangun Masyarakat Madani (Jakarta: Logos, 2000), 210.

"44M. Quraish Shihab, Membumikan Al-Qur'an (Bandung: Mizan, 1997), 201.
} 
dari nilai etisnya. Penyelarasan etika wahyu dan etika rasional merupakan bangunan etis dalam dakwah yang diangkat dalam tulisan ini. Etika tersebut meliputi: Pertama, etika dalam keteladanan. Masyarakat dewasa ini mengalami krisis keteladanan disebabkan berbagai faktor. Tokoh agama, para pemimpin bangsa harus dapat menjadi tauladan bagi masyarakat dengan mengedepankan aspek akhlak, keadilan dan kepemimpinan. Kedua, etika dalam keikhlasan. Lemahnya akhlak dan tuntutan materialisme juga berimplikasi pada kurangnya keikhlasan. Dakwah sebagai sebuah aktivitas memerlukan bingkai nilai-nilai keikhlasan yang kuat agar komitmen niat dapat terjaga dengan baik dan kontinu.

Ketiga, etika dalam pluralisme agama. Pluralisme menghendaki kebersamaan dalam perbedaan. Dakwah dengan cara memaksa pihak lain adalah sikap yang bertentangan dengan nilai-nilai toleransi. Keempat, etika dalam bertauhid. Tauhid adalah sikap pasrah yang mana Tuhan adalah Esa yang layak disandarkan segala urusan dan peribadatan tanpa adanya penyekutuan. Kelima, etika dalam politik. Politik yang sejatinya membawa kemaslahatan masyarakat dapat berubah sebaliknya, manakala tanpa bimbingan moral dan akhlak. Nilai-nilai agama hendaklah dipedomani para politisi, bukan dijadikan lipstik atau bahkan politisasi agama demi kepentingan politik. Keenam, etika dalam globalisasi. Proses globalisasi yang dipicu modernisasi menyisakan sejumlah masalah. Budaya dapat tergerus, masyarakat semakin materialistis dan hedonis. Di sinilah dakwah tampil dalam membingkai dan menyaring budaya asing yang masuk karena proses globalisasi yang tidak dapat dihindarkan.

\section{Daftar Pustaka}

Abdulrahim, Imaduddin. "Sikap Tauhid dan Motivasi Kerja." Jurnal Ulumul Qur'an, Vol. II, No. 6, 1990, 43.

Al-Faruqi, Ismail R. dan Lois Lamya Al-Faruqi. Atlas Budaya Islam, Menjelajah Khazanah Peradaban Gemilang, terj. Ilyas Hasan. Bandung: Mizan, 1998.

Al-Qahtani, Said Bin Ali. Dakwah Islam Dakwah Bijak, terj. Masykur Hakim dan Ubaidillah. Jakarta: Gema Insani Press, 1994.

Amin, Ahmad. Etika (Imu Akblak). Jakarta: Bulan Bintang, 1995. Amir, Mafri, Etika Komunikasi Massa dalam Pandangan Islam.Jakarta: Logos, 1999. 
Aziz, Jum'ah Amin Abdul. Fiqih Dakwah, Studi Atas Berbagai Prinsip dan Kaidah yang Harus dijadikan Acuan Dalam Dakwah Islamiah. terj. Abdul Salam Maskur. Solo: Intermedia, 1998.

Bertens, K.. Etika. Jakarta: Gramedia Pustaka Utama, 2004.

Departemen Pendidikan dan Kebudayaan. Kamus Besar Bahasa Indonesia, Jakarta: Balai Pustaka, 1990.

Dewan Redaksi Ensiklopedi Islam. Ensiklopedi Islam. Jakarta: PT. Ichtiar Baru Van Houve, 1994.

Edi Amin, "Konvergensi Islam dan Negara", Kompas, Jakarta, 27 Desember 1998.

Edwadrs, Paul (ed.), The Encyclopaedia of Philosophy. New York: McMillan Pulishing Co. 1967.

Fakhry, Majid, Etika Dalam Islam. Yogyakarta: Pustaka Pelajar, 1996.

Hasjmy, A. Dustur Dakwah Menurut Al-Quran. Jakarta: Bulan Bintang, 1994.

Hidayat, Komaruddin dan M. Wahyuni Nafis. Agama Masa Depan, Perspektif Filsafat Parenial. Jakarta: Paramadina, 1995.

Hodgson, Marshall G.S. The Venture of Islam, Islam, Iman dan Sejarah dalam Peradaban Dunia, terj. Mulyadhi Kartanegara. Bandung: Mizan, 2002.

Kartanegara, Mulyadhi. Menembus Batas Waktu, Panorama Filsafat Islam. Bandung: Mizan, 2002.

Kontowijoyo. Identitas Politik Umat Islam. Bandung: Mizan, 1997.

Maarif, Ahmad Syafii. "Agama dan Pembangunan: Corak Masyarakat Islam Masa Depan”, Jurnal Ulumul Quran, Vol. III, no. I, 1992.

Maarif, Ahmad Syafii. Membumikan Islam. yogyakarta: Pustaka Pelajar, 1995.

Madjid, Nurcholish, Islam Doktrin dan Peradaban: sebuah Telaah Kritis Tentang Masalah Keimanan, Kemanusiaan dan Kemodernan. Jakarta: Paramadina, 2000.

Madjid. Nurcholish. "Beberapa Renungan Tentang Kehidupan Keagamaan Untuk Generasi Mendatang". Ulumul Quran Jurnal Kebudayaan dan Peradaban, Vol. IV, No. 1, 1993.

Malaikah, Mustafa, Manhaj Dakwah Yusuf Al-Qaradhawi, Harmoni antara Kelembutan dan ketegasan, terj. Samson Rahman. Jakarta: Pustaka Al-Katsar, 2001.

TAJDID Vol. XVI, No. 1, Januari - Juli $2017 \mid 33$ 
Edi Amin

Miskawaih, Ibn, Menuju Kesempurnaan Akblak, terj. Helmi Hidayat. Bandung: Mizan, 1994.

Mubarak, Achmad, Psikologi Dakwah. Jakarta: Pustaka Firdaus, 1999. Muis, A., Komunikasi Islam. Bandung: Rosda, 2001.

Mulyana, Deddy, "Pengantar Etika Komunikasi: Konstruksi Manusia yang Terikat Budaya". Bandung: PT. Remaja Rosdakarya, 1996.

Natsir, M., Fiqhud Dakwah. Jakarta: Yayasan Cipta Selecta, 2000.

Quasem, M. Abul, Etika Al-Ghazali, terj. J. Mahyudin. Bandung: Pustaka, 1988.

Rahman, Fazlur, Islam, terj.. Ahsin Muhammad. Bandung: Pustaka, 1997.

Shihab, M. Quraish. Membumikan Al-Qur'an. Bandung: Mizan, 1997.

Subhani, Ja'far. Studi Kritis Fabam Wababi, Taubid dan Syirik, terj. Muhammad Al-Baqir. Bandung: Mizan, 1996.

Sukadja, Ahmad. Piagam Madinah dan Undang-Undang Dasar 1945, Kajian Perbandingan Tentang Dasar Hiddup Bersama Dalam Masyarakat yang Majemuk. Jakarta: UI-Press, 1995.

Syamsuddin, M. Din. Etika Agama dalam Membangun Masyarakat Madani. Jakarta: Logos, 2000.

Tailor, Paul W. Problems of Moral Pbilosophy. California: Deckenson PublishingCompant Inc., 1992.

Tamara, Nasir dkk. Agama dan Dialog Antar Peradaban. Jakarta: Paramadina, 1996.

Vos, H. De. Pengantar Etika. Yogyakarta: Tiara Wacana, 2002.

Yusuf, M. Yunan. "Dakwah bi-Al-Hal", Jurnal Dakwah Kajian dan Kemasyarakatan, Vol. 3. No. 2, November 2001, 32.

Yusuf, M. Yunan. Internalisasi Etika Islam ke dalam Etika Nasional", Jurnal Dakwah Kajian dan Kemasyarakatan, Vol. I, No. 3, 1999. 